\title{
Control of the Diatropic $\pi$ Ring Current in Strained Benzenes: Effects of Annelation with Cyclopropa, Cyclobuta, and Cyclobutadieno Clamping Groups
}

\author{
Alessandro Soncini, ${ }^{\dagger}$ Remco W. A. Havenith, ${ }^{\dagger}$ Patrick W. Fowler, ${ }^{*}, \dagger$ \\ Leonardus W. J enneskens, ${ }^{*, \ddagger}$ and Erich Steiner ${ }^{\dagger}$ \\ School of Chemistry, University of Exeter, Stocker Road, Exeter EX4 4QD, U.K., and \\ Debye Institute, Department of Physical Organic Chemistry, Utrecht University, Padualaan 8, \\ $3584 \mathrm{CH}$ Utrecht, The Netherlands \\ jennesk@chem.uu.nl; p.w.fowler@exeter.ac.uk \\ Received February 5, 2002
}

\begin{abstract}
Direct visualization of the $\pi$ current density maps of highly strained annelated benzenes containing cyclopropa, cyclobuta, and cyclobutadieno clamps, alone and in combination, using a reliable distributed-origin, coupled Hartree-Fock method, shows the robustness of the classical benzene diatropic $\pi$ ring current. When only saturated clamps are used, the benzene ring current is essentially unchanged. In contrast, annelation with one or more cyclobutadieno clamps disrupts the benzene ring current. Analysis of orbital contributions to the current density maps gives a unified account of these observations in terms of the nature of the HOMO-LUMO transition.
\end{abstract}

\section{Introduction}

Benzenes containing annelated cyclopropa, cycl obuta, and cyclobutadieno rings, alone and in combination (Charts 1-3), have been studied intensively as models for the behavior of aromatic molecules under geometric constraints. ${ }^{1}$ The question has two aspects: does annelation produce significant alterations in the geometry of the central benzene ring, and if it does, are such geometric changes diagnostic of loss of aromatic character? The first aspect has a long history of investigation. ${ }^{1-7}$ The second is the focus of the present work.

The question of whether bond alternation occurs was resolved by convergence of calculation and single-crystal X-ray measurement.1,7 In "simple" cyclopropa- and/or cyclobuta-annelated benzenes, even, e.g., the highly

† University of Exeter.

₹ Utrecht Unniversity.

(1) (a) For a survey: Baldridge, K. K.; Siegel; J . S. J . Am. Chem. Soc. 1992, 114, 9583-9587. (b) Siegel, J . S. Angew. Chem., Int. Ed. Engl. 1994, 33, 1721-1723 and references therein.

(2) F or example: Bloor, J. E.; Eckert-Maksic M.; Hodoscek, M.; Maksic, Z. B.; Poljanec, K. New J'. Chem. 1993, 17, 157-160.

(3) For example: Mitchell, R. H.; Chen, Y.; Iyer, V. S.; Lau, D. Y K.; Baldridge, K. K.; Siegel, J . S. J . Am. Chem. Soc. 1996, 118, $2907-$ 2911. Mitchell, R. H.; Slowey, P. D.; Kamada, T.; Williams, R. V.; Garratt, P. J . J . Am. Chem. Soc. 1984, 106, 2431-2432. Thummel, R. P.; Korp, J . D.; Bernal, I.; Harlow, R. L.; Souren, R. L. J . Am. Chem. Soc. 1977, 99, 6916-6918. Cobbledick, R. E.; Einstein, F. W. B. Acta Crystallogr. 1976, B32, 1908-1909. Thummel, R. P. J . Am. Chem. Soc. 1976, 98, 628-629.

(4) Stanger; A. J . Am. Chem. Soc. 1991, 113, 8277-8280. Stanger, A.; Tkachenko, E. J . Comput. Chem. 2001, 22, 1377-1386 and references therein.

(5) Mills, W. H.; Nixon, I. G. J . Chem. Soc. 1930, 2510-2524.

(6) Faust, R.; Glendening, E. D.; Streitwieser, A.; Vollhardt, K. P. C. J . Am. Chem. Soc. 1992, 114, 8263-8268. Glendening, E. D.; Faust, R.; Streitwieser, A.; Vollhardt, K. P. C.; Weinhold, F. J . Am. Chem. Soc. 1993, 115, 10952-10957 and references therein.

(7) Boese, R.; Bläser, D.; Billups, W. E.; Haley, M. M.; Maulitz, A. H.; Mohler, D. L.; Vollhardt, K. P. C. Angew. Chem., Int. Ed. Engl. 1994, 33, 313-317. strained 1,2,3,4,5,6-hexahydrotricycl obuta[a,c,e]benzene (8), no appreciable bond localization is discernible in calculated geometries. Support for these predictions is given by single-crystal X-ray analyses of 1,2,3,4-tetrahydrodicyclobuta[a,c]- (6), 1,2,3,4,5,6-hexahydrotricyclobuta[a,c,e]- (8), 1,2-dihydrocycl obuta[a]cycl opropa[c]- (9), and 1,2,3,4-tetrahydrodicyd obuta[a,c]cyclopropa[e]benzene (12, Chart 1). ${ }^{7}$ In all compounds, bond localization is found to be minor $(\Delta R \leq 0.025 \AA)$. Apparently, as in the picture favored by Shaik and co-workers, ${ }^{8}$ the rigidity of the $\sigma$ frame of benzene dominates the structures of these annelated derivatives, and as the authors of ref 7 conclude, "benzene, ..., simply wants [sic] to remain 'aromatic"'.

The second aspect of the question remains open. The connection between clamping strain, bond alternation, and aromaticity is complex. It is possible to produce significant bond alternation by clamping: for example, in tris(bicyclo[2.1.1] hexano)benzene (26; $\mathrm{X}$-ray $\Delta \mathrm{R}=$ $0.089 \AA^{9 b}$ and 6-31G** $\Delta R=0.096 \AA^{10}$ ) and tris(benzocyclobutadieno)benzene [27; 11 X-ray (averaged) $\Delta \mathrm{R}=$ $0.159 \AA^{11 b}$ and 6-31G** $\Delta R=0.152 \AA^{10}$ ] (Chart 4). The degree of aromaticity of these molecules, assessed according to magnetic criteria, is markedly different: computed nucleus-independent chemical shifts (NICS ${ }^{12}$ ) for

(8) Shaik, S.; Shurki, A.; Danovich, D.; Hiberty, P. C. Chem. Rev. 2001, 101, 1501-1539 and references therein.

(9) (a) Frank, N. L.; Baldridge, K. K.; Siegel, J. S. J . Am. Chem. Soc. 1995, 117, 2102-2103. (b) Burgi, H.-B.; Baldridge, K. K.; Hardcastle, K.; Frank, N. L.; Gantzel, P.; Siegel, J . S.; Ziller, J. Angew. Chem., Int. Ed. Engl. 1995, 34, 1454-1456. (c) See also Matsuura, A.; Komatsu, K. J . Am. Chem. Soc. 2001, 123, 1768-1769.

(10) F owler, P. W.; Havenith, R. W. A.; J enneskens, L. W.; Soncini, A.; Steiner, E. Chem. Commun. 2001, 2386-2387.

(11) (a) Diercks, R.; Vollhardt, K. P. C. J . Am. Chem. Soc. 1986, 108, 3150-3152. (b) Holmes, D.; Kumaraswamy, S.; Matzger, A. J .; Vollhardt, K. P. C. Chem. Eur. J . 1999, 5, 3399-3412 and references therein. 


\section{CHART 1. Cyclopropa- and Cyclobuta-Annelated Benzenes 1-12a}

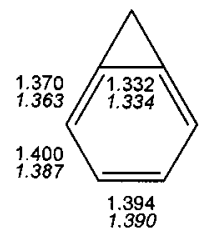

$1, C_{2 v}$

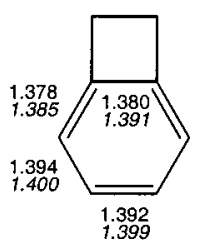

5, $C_{2 v}$

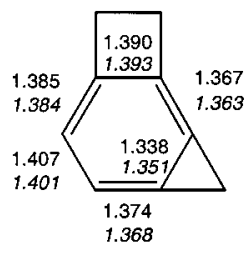

$9, C_{s}$

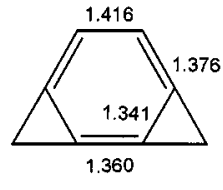

2, $C_{2 v}$

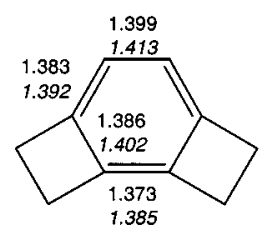

6, $C_{2 v}$

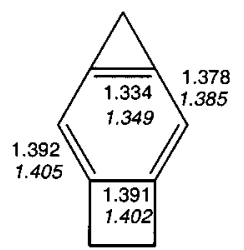

$10, C_{2 v}$

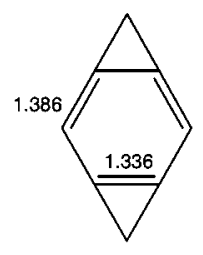

3, $D_{2 h}$

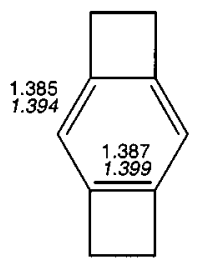

7, $D_{2 h}$

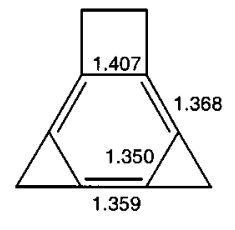

$11, C_{2 v}$

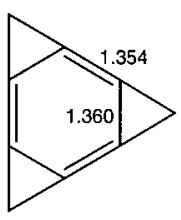

4. $D_{3 h}$

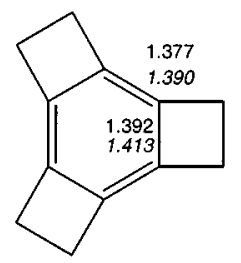

8, $D_{3 h}$

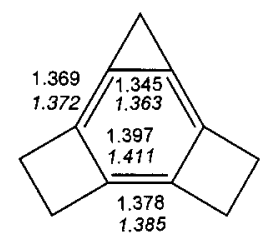

$12, C_{2 v}$

a Bond lengths $(\AA)$ calculated at the RHF/6-31G** level are indicated for the benzene ring; values from (averaged) single-crystal X-ray measurements $7,18-20$ are indicated in italic type.

\section{CHART 2. Cyclobutadieno- and Cyclopropa-Annelated Benzenes 13-20a}

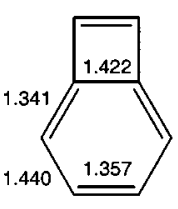

$13, C_{2 v}$

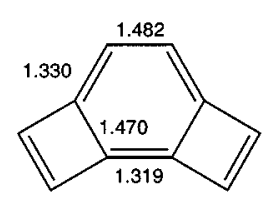

$14, C_{2 v}$

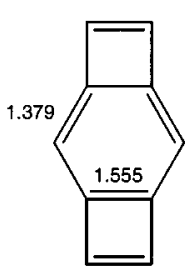

$15, D_{2 h}$

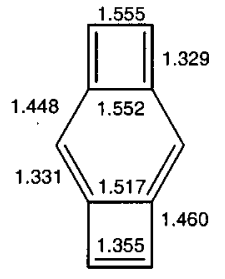

15, $C_{2 v}$

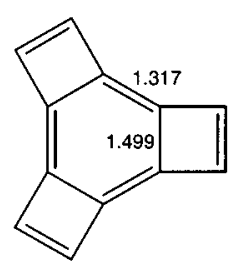

$16, D_{3 h}$

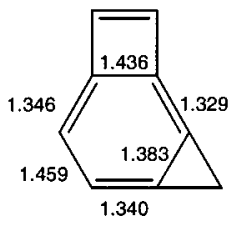

$17, C_{s}$

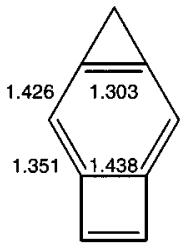

18, $C_{2 v}$

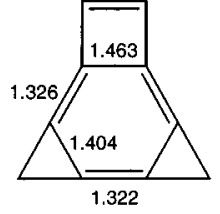

$19, C_{2 v}$

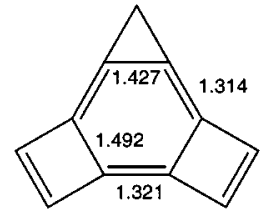

$20, C_{2 v}$

a Bond lengths $(\AA)$ calculated at the RHF/6-31G** level.

the central benzene rings $\left[\mathbf{2 6},-8.0 \mathrm{ppm}(0.0 \AA)^{9 \mathrm{C}}\right.$ and $\mathbf{2 7}$, $\left.-1.1 \mathrm{ppm}(1.0 \AA)^{13}\right]$ and direct visualization of induced current density ${ }^{10}$ are in agreement in predicting that $\mathbf{2 6}$ is aromatic, whereas $\mathbf{2 7}$ is not. The maps for $\mathbf{2 6}$ show

(12) Schleyer, P. v. R.; Maerker, C.; Dransfeld, A.; J iao, H.; van Eikema Hommes, N. J. R. J . Am. Chem. Soc. 1996, 118, 6317-6318. Schleyer, P. v. R.; Manoharan, M.; Wang, Z.-X.; Kiran, B.; J iao, H.; Puchta, R. van Eikema Hommes, N. J . R. Org. Lett. 2001, 3, 24652468.

(13) Schulman, J . M.; Disch, R. L.; J iao, H.; Schleyer, P. v. R. J . Phys. Chem. A 1998, 102, 8051-8055. that the classical diatropic $\pi$ ring current is retained, but for 27, the ring current in the central benzene is quenched and replaced by localized ethene-like moieties, indicating that its central benzene ring resembles a 1,3,5cycl ohexatriene (see also ref 14). A proposed rationalization in terms of orbital contributions to the current

(14) The 1,3,5-cyclohexatriene character of the central benzene ring in $\mathbf{2 7}$ is in line with its heat of hydrogenation; Beckhaus, H.-D.; F aust, R.; Matzger, A. J .; Mohler, D. L.; Rogers, D. W.; Ruechardt, C.; Sawhney, A. K.; Verevkin, S.; Vollhardt, K. P. C.; Wolff, S. J . Am. Chem. Soc. 2000, 122, 7819-7820. 
CHART 3. Cyclobutadieno-, Cyclobuta-, and Cyclopropa-Annelated Benzenes 21-25a

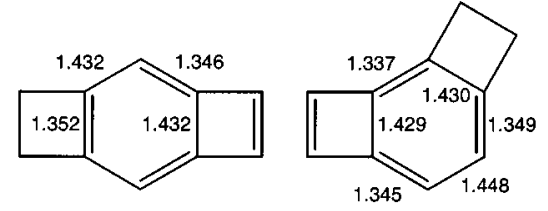

21, $C_{2 v}$

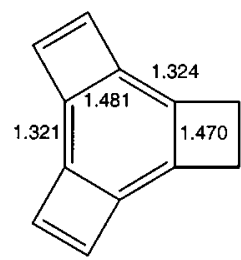

24, $C_{2 v}$

22, $C_{s}$

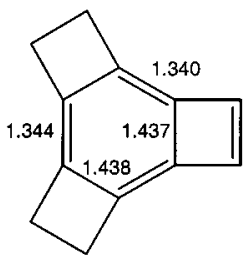

23, $C_{2 v}$

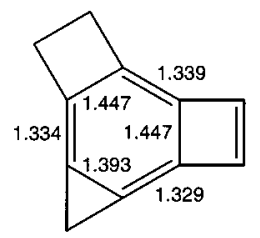

25, $C_{s}$

a Bond lengths $(\AA)$ calculated at the RHF/6-31G** level.

CHART 4. Tris(bicyclo[2.1.1]hexano)- (26) and Tris(benzocyclobutadieno)benzene (27)

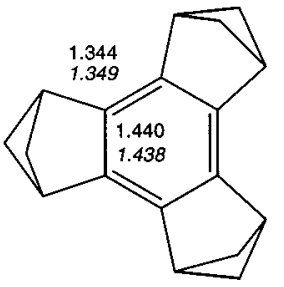

26, $D_{3 h}$

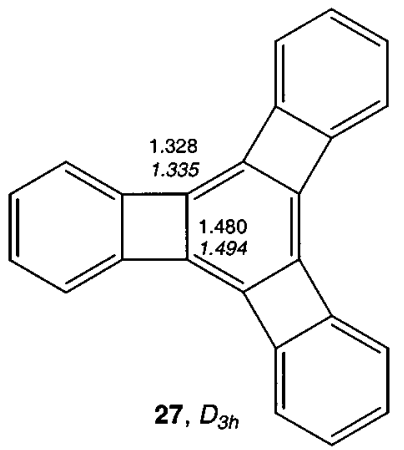

a Bond lengths $(\AA)$ calculated at the RHF/6-31G** level are indicated for the benzene ring; values from (averaged) singlecrystal X-ray measurements ${ }^{9 b, 11}$ are indicated in italic type.

density ${ }^{10,15}$ is extended here to the whole family of cyclopropa-, cyclobuta-, and cyclobutadieno-annelated benzenes. The persistence of benzenoid aromaticity, in the magnetic sense, for saturated clamping groups, and its destruction by unsaturated groups, is demonstrated by calculation. Orbital effects, and not the degree of bond alternation, emerge as the controlling factors in the aromaticity of benzene as evaluated on the magnetic criterion. ${ }^{15}$

\section{Results}

The test set of molecules consists of the 25 structures formed by annelation to a benzene ring of one, two, or three bridges chosen from cyclopropa, cyclobuteno, and cyclobutadieno moieties, in all possible combinations (Charts 1-3). Each structure $\mathbf{1 - 2 5}$ was optimized at the RHF level in the 6-31G** basis set (Gaussian 98,16 GAMESS-UK ${ }^{17}$ ), and energy minima were checked by diagonalization of the Hessian. All molecules were found to have planar carbon skeletons, and all but $\mathbf{1 5}$ have the maximum symmetry expected from their molecular graphs

(15) (a) Steiner, E.; Fowler, P. W. Chem. Commun. 2001, 22202221. (b) Steiner, E.; F owler, P. W. J . Phys. Chem. A 2001, 105, 95539562.
(15 has $C_{2 v}$ rather than $D_{2 h}$ symmetry, with two short bonds in the benzene ring; see Chart 2 and the Supporting I nformation).

For the 6-31G**-optimized geometries of compounds $\mathbf{2 6}$ and $\mathbf{2 7}$ see ref 10. At the 6-31G** RHF level, benzene itself has $R_{C C}=1.386 \AA$ and $R_{C H}=1.076 \AA$. In molecules 1-12, the central ring shows small angular distortions and variation in bond length compatible with the molecular symmetry, but as noted in earlier work, the degree of bond alternation in these systems is not large, and in particular, it gives no evidence for a Mills-Nixon effect ${ }^{1-7,18-20}$ of annelation of small rings. A comparison of the computed bond lengths with those found in the available single-crystal X-ray structures of $\mathbf{1},{ }^{18} \mathbf{5},{ }^{19} \mathbf{6},{ }^{7}$ $\mathbf{8}^{7}{ }^{7},{ }^{7} \mathbf{1 0},{ }^{20}$ and $\mathbf{1 2}^{7}$ shows a satisfactory agreement. Variation in bond length within the central ring is larger for the mol ecules with cyclobutadieno clamps but is still small compared with the difference between formal single (1.54 $\AA$ ) and double (1.34 $\AA$ ) bonds.

To diagnose the variation in magnetic properties within the test set, current-density maps (ring-current maps) were constructed using the standard distributedorigin CTOCD-DZ ${ }^{21}$ method (SYSM O ${ }^{22}$ ) in the same basis used for the geometry optimization. Figures 1-3 show the results. For each molecule, the current density induced in the $\pi$-electron distribution by a perpendicular magnetic field is plotted at a fixed height above the molecular plane. A height of $1 a_{0}$ is chosen to lie near the maxima of $\pi$ charge and current densities; the vectors in the plots represent the projection of the current density in the plotting plane. ${ }^{23} \mathrm{~A}$ component of current density perpendicular to the plotting plane is allowed by symmetry but is small at this height above the molecule. ${ }^{24,25}$

(16) GAUSSIAN98 (Revision A.9): Frisch, M. J .; Trucks, G. W.; Schlegel, H. B.; Scuseria, G. E.; Robb, M. A.; Cheeseman, J. R.; Zakrzewski, V. G.; Montgomery, J. A.; Stratmann, R. E.; Burant, J. C.; Dapprich, S.; Millam, J. M.; Daniels, A. D.; Kudin, K. N.; Starin, M. C.; Farkas, O.; Tomasi, J .; Barone, V.; Cossi, M.; Cammi, R.; Mennucci, B.; Pornelli, C.; Adamo, C.; Clifford, S.; Ochterski, J .; Petersson, G. A.; Ayala, P. Y.; Cui, Q.; Morokuma, K.; Malick, D. K. Rabuck, A. D.; Raghavachari, K.; Foresman, J . B.; Cioslowski, J .; Ortiz, J. V.; Stefanov, B. B.; Liu, G.; Liashenko, A.; Piskorz, P.; Komaromi, 1.: Gomperts, R.; Martin, R. L.; Fox, D. J ; Keith, T.; Al-Laham, M. A. Peng, C. Y.; Nanayakkara, A.; Gonzalez, C.; Challacombe, M.; Gill, P. M. W.; J ohnson, B. G.; Chen, W.; Wong, M. W.; Andres, J. L.; HeadGordon, M.; Replogle, E. S.; Pople, J . A. Gaussian, Inc, Pittsburgh PA, 1998.

(17) Guest, M. F.; van Lenthe, J. H.; Kendrick, J .; Schöffel, K.; Sherwood, P.; Harrison, R. J. GAMESS-UK, a package of ab initio programs, 2000. With contributions from: Amos, R. D.; Buenker, R. J .; Dupuis, M.; Handy, N. C.; Hillier, I.; Knowles, P. J .; BonacicKoutecky, V.; von Niessen, W.; Saunders: V. R.; Stone, A. J. It is derived from the original GAMESS code due to M. Dupuis, D. Spangler, J . Wendolowski, NRCC Software Catalog, Vol. 1, Program N o. QG01 (GAMESS), 1980.

(18) Neidlein, R.; Christen, D.; Poignée, V.; Boese, R.; Bläser, D.; Gieren, A.; Ruiz-Pérez, C.; Hübner, T. Angew. Chem., Int. Ed. Engl. 1988, 27, 294-295.

(19) Boese, R.; Bläser, D. Angew. Chem., Int. Ed. Engl. 1988, 27, 304-305.

(20) Bläser, D.: Boese, R.; Brett, W. A.; Rademacher, P.: Schwager, H.; Stanger, A.; Vollhardt, K. P. C. Angew. Chem., Int. Ed. Engl. 1989, 28, 206-208.

(21) (a) Keith, T. A.; Bader, R. F. W. Chem. Phys. Lett. 1993, 210 223-231. (b) Coriani, S.; Lazzeretti, P.; Malagoli, M.; Zanasi, R. Theor. Chim. Acta 1994, 89, 181-192. (c) See also: Steiner, E.; Fowler, P. W.; J enneskens, L. W. Angew. Chem., Int. Ed. Engl. 2001, 40, 362366.

(22) Lazzeretti, P.; Zanasi, R. SYSMO Package; University of Modena: Modena, Italy, 1980, with additional routines for evaluation and plotting of current density by E. Steiner and P. W. Fowler.

(23) Soncini, A.; Fowler, P. W.; Cernušak, I.; Steiner. E. Phys. Chem. Chem. Phys. 2001, 3, 3920-3923 and references therein. 

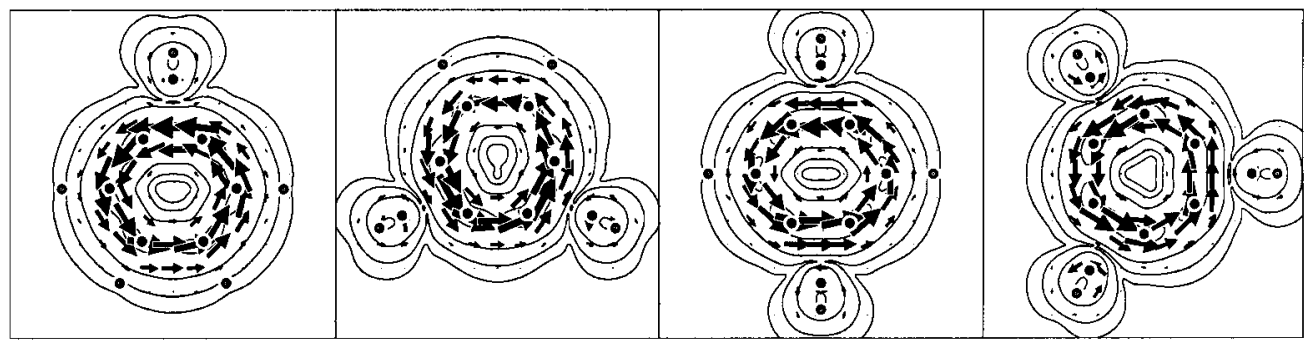

1

2

3

4

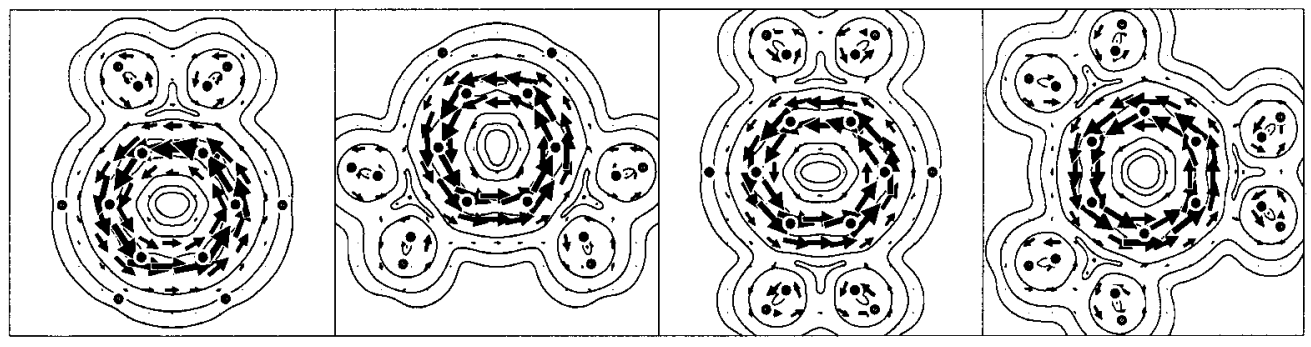

5

6

7

8

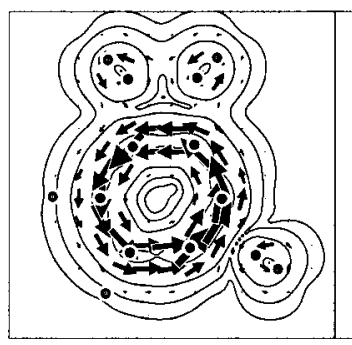

9

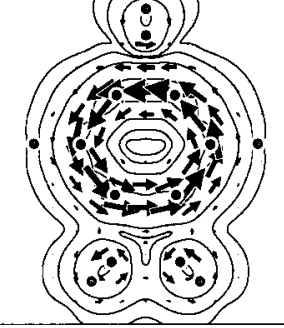

10

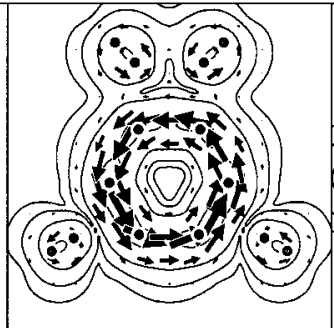

11

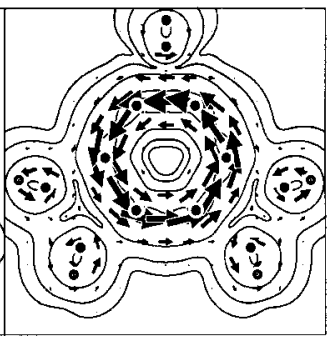

12

FIGURE 1. Computed $\pi$-only current density maps of 1-12. The arrows show the magnitude and direction of the projection of the current density $\mathrm{j}$ in the plotting plane; the dots indicate projected nuclear positions.

At this height, the current flow is essentially parallel to the molecular plane, and the map does indeed represent an ab initio visualization of the organic chemist's ideal of a $\pi$ ring current, where such currents exist in particuIar molecules.

The $\sigma$ contribution to the current-density maps is not shown here explicitly, but for all molecules 1-25, the $\sigma$ current has the usual features. At $1 \mathrm{a}_{0}$ above the plane, the intense diamagnetic currents density around the nuclei is invisible. The $\sigma$ maps exhibit distributions characteristic of localized covalent bonds in which each $\sigma$ bond is a center of diamagnetic circulation, and as a consequence, there is a cumulative localized paramagnetic $\sigma$ circulation at the center of each ring (see also refs 21c and 26).

\section{Discussion}

A remarkably simple dichotomy is revealed by even a cursory inspection of the full set of maps. In all those

(24) Černušak, I.; Fowler, P. W.; Steiner, E. Mol. Phys. 1997, 91, 401-412

(25) Ligabue, A.; Soncini, A.; Lazzeretti, P. J . Am. Chem. Soc. 2002, 124, 2008-2014

(26) Steiner, E.; Fowler, P. W.; J enneskens, L. W.; Acocella, A. Chem. Commun. 2001, 659-660. Steiner, E.; Fowler, P. W.; J enneskens, L. W.; Havenith, R. W. A. Eur. J . Org. Chem. 2002, 163-169. molecules composed of a central benzene ring annelated with fully saturated bridges (1-12), the map shows a single, central, diatropic $\pi$ ring current (Figure 1 ). The current is substantially uniform and follows the circuit of bonds. Clearly, some small modulations in its shape, symmetry, and intensity are discernible. Nevertheless, all molecules in this class have the archetypal benzene aromatic ring current. As Table 1 shows, there is little variation in the $\pi$ current density; as measured by $\mathrm{j}_{\max }$, the maximum projection of the current density expressed as the ratio to the corresponding quantity in benzene itself (Table 1). The computed ring current in 26 also follows this classical pattern, ${ }^{10}$ albeit with a greater reduction in intensity.

In contrast, the $\pi$ current density maps for all remaining structures (13-25, see Figures 2 and 3) show no significant circulation in the central benzene ring. Whenever there is at least one unsaturated cyclobutadieno bridge, the central current is weakened (e.g., 13, 18, and 21) or disrupted (e.g., 16, 20, and 24), and the $\pi$ map for molecules with one cyclobutadieno group is dominated by a strong paratropic current within the unsaturated four-membered ring. For comparison with Table 1, the molecules 13, 15, 17-19, 21-23, and 25 have $j_{\max }$ in the range 1.17-1.48, where this value refers to the paratropic circulation over the four-membered ring. In the 3-fold 


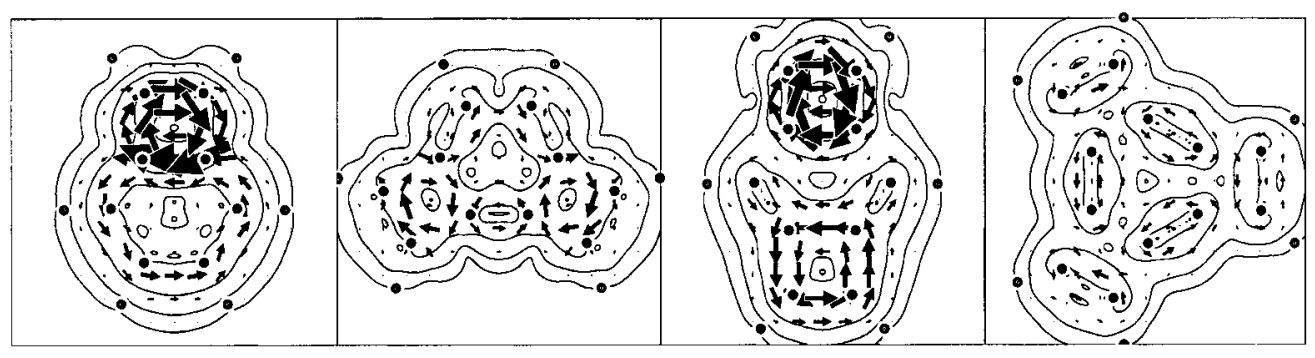

13

14

15

16

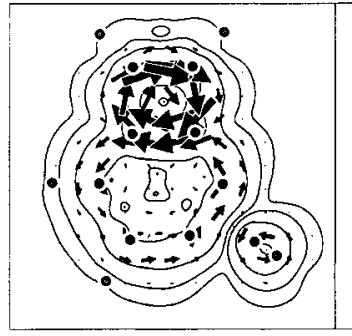

17

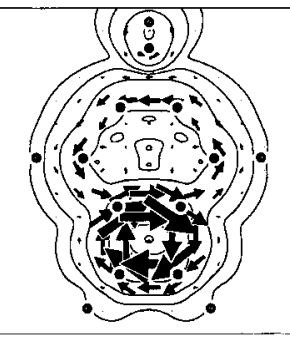

18

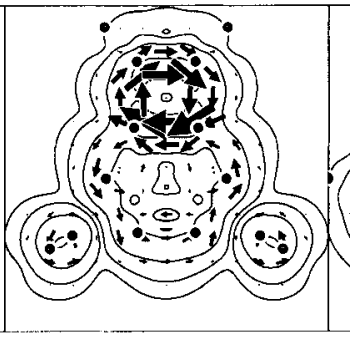

19

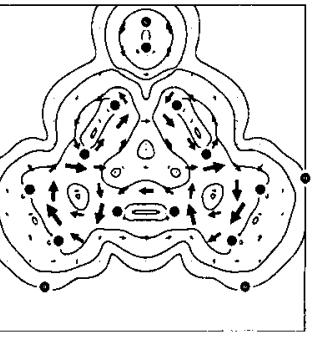

20

FIGURE 2. Computed $\pi$-only current density maps of 13-20. Plotting details as in Figure 1.

symmetric tris(cyclobutadieno)benzene (16), disruption of the central benzene motif proceeds so far that it produces a classical example of a fully localized pattern, one that is indicative of a set of three isolated double bonds; as noted above, the same pattern is found in the $\pi$ current density map of $\mathbf{2 7}$ (see ref 10 ). The molecules $\left(\mathbf{1 4}, \mathbf{1 6}, \mathbf{2 0}, \mathbf{2 4}\right.$, and $\mathbf{2 7}{ }^{10}$ ) have the small values of $j_{\max }$ (here, $\leq 0.61$ ) characteristic of localized $\pi$ bonds.

The maps themselves, therefore, provide an answer to the second question posed in the Introduction. If the magnetic criterion of aromaticity is applied, then the aromatic character of benzene survives intact in all of the species 1-12 and $\mathbf{2 6}$ but is destroyed in 13-25 and 27. A more interesting question is, of course, the origin of the separation between cyclopropano- and cyclobutanoannelated benzenes on one hand and cyclobutadienoannelated benzenes on the other.

The CTOCD-DZ method, in addition to its role in providing overall patterns of ring currents, also gives the key to a rationalization of their differences. In common with other reliable methods of computation of magnetic properties, the CTOCD-DZ approach uses a distributed origin of vector potential. ${ }^{21}$. In CTOCD-DZ, the origin for calculation of current density at any point is taken to be the point itself. This ipsocentric feature of the method has been used to derive a specific partition of the firstorder wave function and, therefore, of the induced current density, into orbital contributions that involve only occupied-to-virtual transitions and obey simple symmetry-based selection rules. ${ }^{15}$ In a $\pi$ system subjected to a perpendicular magnetic field, nonvanishing orbital contributions arise only from transitions that are induced by either in-plane translations or rotation about the field direction. Expressed with respect to the molecular center, the contributions of the first type are diatropic and those of the second are paratropic.

In this orbital-based picture, the ring current in a (4n $+2) \pi$-electron monocycle, such as benzene, arises from the four electrons active in the translationally allowed HOMO-LUMO transition. In Hückel theory, this would be the sole allowed transition, ${ }^{15 a}$ and in more sophisticated models it remains dominant. ${ }^{15 b}$

The orbital explanation for the survival of the benzene ring current in molecules $\mathbf{1 - 1 2}$ and $\mathbf{2 6}^{10}$ is therefore clear. In all of these systems, the HOMO orbitals are essentially unperturbed, with orbital energies lying in a narrow range $\left[\epsilon_{\text {номо }}=(-0.31 \pm 0.01) \mathrm{E}_{\mathrm{h}}(-8.4 \mathrm{eV})\right]$. They are $p_{\pi}$ orbitals localized on the central ring, with a small energy splitting in low-symmetry cases, but with the same nodal character as in the parent benzene molecule.

Likewise, the LUMO is of benzenoid $\pi^{*}$ character ( $\epsilon_{\text {LUMO }}$ $=(+0.14 \pm 0.015) \mathrm{E}_{\mathrm{h},} \mid \epsilon_{\text {HOMO }}-\epsilon_{\text {LUMO }}=(0.443 \pm 0.016)$ $E_{h}$ ). The HOMO-LUMO $\pi-\pi^{*}$ transition remains dominant, and the diatropic benzene ring current survives with essentially the same strength as in benzene itself.

The reason for the alteration of this current in 13-25 and $\mathbf{2 7 ^ { 1 0 }}$ is equally clear. I ncorporation of an unsaturated annelated ring introduces new orbitals into the $p_{\pi}$ manifold, and interaction between these and the orbitals of the central ring produces a new set of MOs in which the HOMO and LUMO are spread out over the whole $\pi$ system. The change in character is reflected in a greater spread $\left(\sim 0.07 \mathrm{E}_{h}\right)$ in both HOMO and LUMO eigenvalues and a smaller HOMO-LUMO gap (typically, $0.3-0.4 \mathrm{E}_{\mathrm{h}}$ ). The particular orbital-interaction diagrams for $\mathbf{8}$ and $\mathbf{1 6}$ are al ready reported as Figure 2 of ref 10, and Figure 4 of the present paper illustrates in a highly stylized form this contrast between systems with unsaturated $\left(\pi / \pi^{*}\right)$ and saturated $\left(\sigma / \sigma^{*}\right)$ clamping groups.

\section{Conclusions}

An exploration of strained benzene species has shown the robustness of the classical benzene diatropic $\pi$ ring current and indicated the way in which this current can be disrupted. The orbital analysis natural to the ipso- 


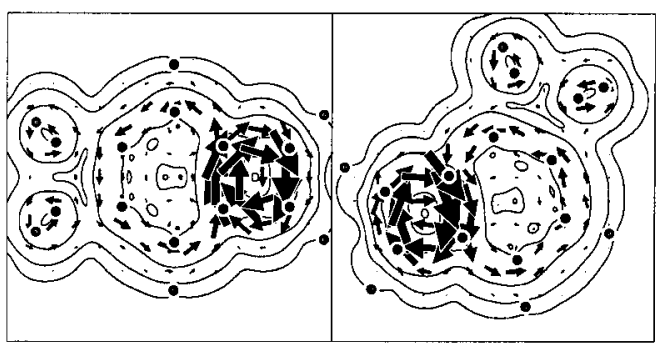

21

22

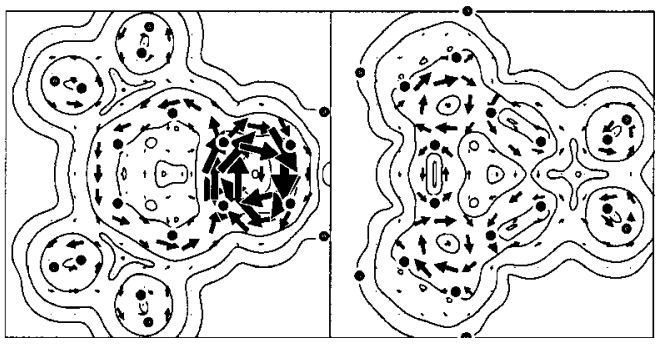

23

24

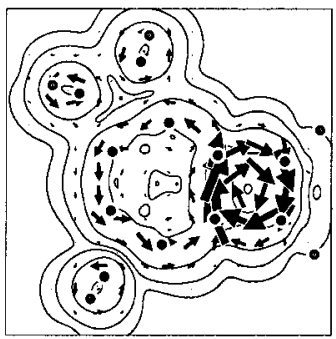

25

FIGURE 3. Computed $\pi$-only current density maps of $\mathbf{2 1 -}$ 25. Plotting details as in Figure 1.

centric CTOCD-DZ distributed-origin approach exposes the distinction between unsaturated and saturated damping groups in terms of their effect on the critical HOMOLUMO transition. These arguments have implications for many other systems. F or example, it has been shown ${ }^{9 c, 27}$ that the cyclooctatetraene (COT) moiety when planarized with the fully saturated bicyclo[2.1.1] hexano clamping group exhibits the strong paratropic current expected on classical Hückel arguments. The orbital model further predicts that this current will be retained or disrupted in other derivatives of COT according to the saturation or unsaturation of the clamps. Computed current density

(27) Fowler, P. W.; Havenith, R. W. A.; J enneskens, L. W.; Soncini, A.; Steiner, E. Angew. Chem., Int. Ed. 2002, 41, 1558-1560.
TABLE 1. Variation in $\pi$ Current Density in Annelated Benzenes (1-12 and $\left.26^{10}\right)^{a}$

\begin{tabular}{cccc}
\hline compd & $\mathrm{j}_{\max }$ & compd & $\mathrm{j}_{\max }$ \\
\hline $\mathbf{1}$ & 1.15 & $\mathbf{8}$ & 1.01 \\
$\mathbf{2}$ & 1.08 & $\mathbf{9}$ & 1.13 \\
$\mathbf{3}$ & 1.08 & $\mathbf{1 0}$ & 1.11 \\
$\mathbf{4}$ & 0.99 & $\mathbf{1 1}$ & 1.04 \\
$\mathbf{5}$ & 1.07 & $\mathbf{1 2}$ & 1.09 \\
$\mathbf{6}$ & 1.04 & $\mathbf{2 6}$ & $0.80^{10}$ \\
$\mathbf{7}$ & 1.03 & &
\end{tabular}

${ }^{a} j_{\max }$ is the maximum projection of the current density in the plotting plane, expressed as a ratio to the corresponding quantity for benzene itself. The maximum occurs over the benzene ring in 1-12.

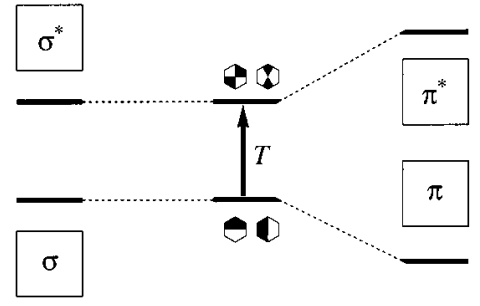

FIGURE 4. Effects of clamping on the electronic structure of benzene. I $n$ benzene itself (center), the ring current arises from a translationally (T) allowed HOMO-LUMO transition. ${ }^{15}$ When saturated groups are attached (left), this transition is undisturbed, as the extra (usually $\sigma$ ) orbitals from the clamping group lie outside the active $\pi$ space, but when unsaturated groups are attached (right), other magnetically active orbitals intrude into the frontier region (see also ref 10 ).

maps for COT analogues of $\mathbf{8}$ and $\mathbf{1 6}$ (see ref 27) are in exact agreement with this prediction. Despite the difference in the orbital origin of diatropic and paratropic ring currents, ${ }^{15}$ the underlying explanation in terms of intruder orbitals remains valid.

Acknowledgment. We acknowledge a travel grant from the Royal Society of Chemistry (International Travel Grant No. 0012289; L.W.J .) and financial support from the European Union (TMR Contract No. FMRXCT097-0192 (R.W.A.H.) and the Marie-Curie scheme HPMT-CT-2000-00016 (A.S.)).

Supporting Information Available: Table containing the RHF/6-31G** total energies and NIMAG values of compounds 1-25 and Cartesian coordinates of RHF/6-31G**-optimized geometries of compounds $\mathbf{1 - 2 7}$. This material is available free of charge via the Internet at http://pubs.acs.org.

J O020091D 